\title{
ASSESSMENT ON THE LEVEL OF KNOWLEDGE OF WOMEN OF REPRODUCTIVE AGE GROUP ABOUT POLYCYSTIC OVARIAN SYNDROME (PCOS) AND ITS EFFECT ON REPRODUCTIVE HORMONES.
}

\author{
Oriji Eunice Ibiye $^{1^{*}}$, Ojeka Sunday Ogbu² and Zabbey Victor Zigabelbari ${ }^{2}$ \\ ${ }^{1}$ Department of Human Physiology, Faculty of Basic Medical Sciences, College of Health Science, Rivers State University, Nigeria. \\ ${ }^{2}$ Department of Human Physiology, Faculty of Basic Medical Sciences, College of Health Science, University of Port Harcourt, \\ Rivers State, Nigeria. \\ E-mail: ibiyeabere@gmail.com, sunday.ojeka@uniport.edu.ng, zabbeyvictor@gmail.com \\ *Address for correspondence \\ Dr Oriji Eunice Ibiye \\ Department of Human Physiology, Faculty of Basic Medical Sciences, College of Health Science, Rivers State University, Rivers \\ State, Nigeria. \\ E-mail: ibiyeabere@gmail.com \\ Phone: +2348031390948
}

DOI: $10.31364 /$ SCIRJ/v9.i10.2021.P1021890

http://dx.doi.org/10.31364/SCIRJ/v9.i10.2021.P1021890

\begin{abstract}
Polycystic ovarian syndrome (PCOS) refers to the presence of small, benign and painless cysts in the ovaries, usually manifested clinically by a faction of symptoms and changes in hormonal levels. Despite the fact that its prevalence is global, the knowledge of its etiology and management is still grossly inadequate even among women who are affected in various parts of the world. The study therefore investigated the level of knowledge of women of reproductive age group about polycystic ovarian syndrome and its effect on the reproductive hormones. A sample of ninety-four (94) subjects, consisting of forty-seven (47) PCOS women and forty-seven (47) non-PCOS women with age ranging from 15-50 years was used for the study, to evaluate their knowledge of PCOS and its effect on their reproductive hormones. A structured questionnaire was used to collect data from the respondents. The results showed that PCOS is mainly found among married women within the age of 21 to 30 years. The knowledge of the respondents about PCOS was also found to be very poor with only about $40.43 \%$ of them indicating having knowledge about the condition. Finally, PCOS was found to significantly elevate the concentrations of LH and FSH, significantly reduced the concentration of Progesterone, with an insignificant effect on prolactin, with respect to the non-PCOS patients. It was therefore concluded that the women in this study generally have a poor knowledge about the existence of PCOS and that PCOS has the capacity to cause hormonal imbalance.
\end{abstract}

Keywords: Ovaries, women, Perception, Hormones, Attitudes, Questionnaire and PCOS

www.sciri.org

(C) 2021, Scientific Research Journal

http://dx.doi.org/10.31364/SCIRJ/v9.i10.2021.P1021890

This publication is licensed under Creative Commons Attribution CC BY. 


\section{INTRODUCTION}

Polycystic ovarian syndrome (PCOS) refers to the presence of small, benign and painless cysts in the ovaries, usually manifested clinically by a faction of symptoms and changes in hormonal levels. It is a hormonal disorder resulting in enlarged ovaries with small cysts on the outer edges or many small, fluid-filled sacs growing inside the ovaries. Although these cysts are not usually harmful, they can lead to an imbalance in hormone levels. PCOS is said to be the most common cause of infertility in women. ${ }^{[1]}$ Although the exact cause of PCOS is not known, it is generally believed to result in hormonal imbalance, hence it has been alternatively called "ovarian androgen excess" This is so because in patients with PCOS, the ovaries begin to produce androgen in increased amounts.

One of the factors associated with PCOS include type 2 diabetes, infertility, miscarriage, obesity, metabolic syndrome, depression and anxiety. ${ }^{[2]}$ Others include abnormal uterine bleeding, pregnancy induced high blood pressure, high cholesterol and elevated lipids. Polycystic ovarian syndrome is among the most common causes of disorders of the endometrium in women globally. ${ }^{[3]}$

Diagnosing PCOS is always a difficult task, since it often involves a diagnosis that is reached by the exclusion of other medical conditions that cause irregular menstrual cycles and excess androgen. The present clinical approach to diagnosing polycystic ovary syndrome therefore depends on symptoms and signs, or hormonal testing and ultrasound scanning. ${ }^{[4]}$

Despite the fact that the prevalence of PCOS is global, the knowledge of its etiology and management is still grossly inadequate even among women who are affected in various parts of the world. Also, although most studies have focused more on determining the prevalence of PCOS among women of Nigeria, only a few have attempted to assess the knowledge of PCOS in the south - south region of Nigeria. ${ }^{[5]}$ There is therefore the need to carry out a cross-sectional survey to evaluate the knowledge of women of reproductive age group towards PCOS and its effect on the reproductive hormones in Port Harcourt, Rivers Nigeria.

\section{MATERIALS AND METHODS}

Interviewer-administered questionnaires were used to obtain information from the respondents which consist of both healthy women and women suffering from PCOS and with age ranging from 15-50 years in some health facilities in Port Harcourt, to assess their level of knowledge on polycystic ovarian syndrome (PCOS) and its effect on their reproductive hormones. The random sampling method was used to select a total sample size of ninety-four (94) subjects, consisting of forty-seven (47) PCOS patients and fortyseven (47) healthy women as the sample size. This study was carried out in 4 major health facilities in Port Harcourt, Rivers State.

The semi-structured interviewer-administered questionnaire used for this study was divided into three sections to obtain the data for this study. The first section (Section A) contains questions on the socio-demographic characteristics of the respondents, the second section (Section B) contains questions on the knowledge of the respondents about the existence and symptoms of PCOS while the third section (Section C) contains the information on the concentration of some major female reproductive hormones.

www.sciri.org

(C) 2021, Scientific Research Journal

http://dx.doi.org/10.31364/SCIRJ/v9.i10.2021.P1021890

This publication is licensed under Creative Commons Attribution CC BY. 
Analysis of the reproductive hormones were gotten using the boditech ichromax TM machine with the various hormonal assay kits. Analysed values were presented in tables. Mean comparison (descriptive analysis) was done with student T-Test at a confidence limit of $95 \%$, groups differences were considered significant at $\mathrm{p}<0.05$. The concentration of the reproductive hormones obtained from the respondents was compared with those of normal healthy individuals of the same age group. Results were shown as mean \pm standard error of mean.

The permission to conduct the study was sought and obtained from the University of Port Harcourt Ethical Committee and the health facilities. Also, Consent was sought and obtained from the respondents before the commencement of the interview. The benefits of the study were explained to the respondents. Assurance was also given to them that the information about them will be handled with an utmost confidentiality. The confidentiality of all respondents was guaranteed by excluding the use of identifiers such as names, address and other information that can reveal the identity of the research participants.

\section{RESULTS}

Table 1: Distribution of Respondents by Socio-Demographic characteristics

\begin{tabular}{|c|c|c|}
\hline Variables & Frequency $(\mathrm{N}=94)$ & Percentage (\%) \\
\hline \multicolumn{3}{|c|}{ Age } \\
\hline $11-20$ & 8 & 8.51 \\
\hline $21-30$ & 56 & $\mathbf{5 9 . 5 7}$ \\
\hline $31-40$ & 25 & 26.60 \\
\hline Above 40 & 5 & 5.32 \\
\hline \multicolumn{3}{|c|}{ Marital status } \\
\hline Single & 40 & 42.55 \\
\hline Married & 48 & 51.06 \\
\hline Divorced & 6 & 6.38 \\
\hline \multicolumn{3}{|c|}{ Level of education } \\
\hline No education & $\mathbf{0}$ & $\mathbf{0}$ \\
\hline Primary & 8 & 8.51 \\
\hline Secondary & 38 & 40.43 \\
\hline Tertiary & 48 & 51.06 \\
\hline \multicolumn{3}{|c|}{ BMI $\left(\mathrm{Kg} / \mathbf{M}^{2}\right)$} \\
\hline Normal & 26 & 27.66 \\
\hline Overweight & 38 & 40.43 \\
\hline Obese & 26 & 27.66 \\
\hline Extremely obese & 4 & 4.26 \\
\hline
\end{tabular}




\begin{tabular}{|l|c|c|}
\hline \multicolumn{3}{|c|}{ Age of diagnosis } \\
\hline Adolescents (<18years) & $\mathbf{1 0}$ & $\mathbf{1 0 . 6 4}$ \\
\hline Middle aged (18 to 45 years) & $\mathbf{8 4}$ & $\mathbf{8 9 . 3 6}$ \\
\hline Adult (>45years) & $\mathbf{0}$ & $\mathbf{0}$ \\
\hline
\end{tabular}

Table 2: Knowledge of Respondents about PCOS

\begin{tabular}{|c|c|c|c|c|}
\hline \multirow[t]{2}{*}{ Variables } & \multicolumn{2}{|c|}{ Yes } & \multicolumn{2}{|c|}{ No } \\
\hline & $\begin{array}{l}\text { Frequency } \\
\text { (94) }\end{array}$ & $\begin{array}{l}\text { Percentage } \\
(\%)\end{array}$ & Frequency (94) & $\begin{array}{c}\text { Percentage } \\
(\%)\end{array}$ \\
\hline Did you have any idea about PCOS before now? & 38 & 40.43 & 56 & 59.57 \\
\hline \multicolumn{5}{|c|}{ If yes, from who/where did you hear about it? } \\
\hline \multicolumn{5}{|l|}{ No answer } \\
\hline Friend & 10 & 10.64 & 84 & 89.36 \\
\hline Health worker & 20 & 21.28 & 74 & 78.72 \\
\hline Internet & 20 & 21.28 & 74 & 78.72 \\
\hline Relatives & 12 & 12.77 & 82 & 87.23 \\
\hline Newspaper & 10 & 10.64 & 84 & 89.36 \\
\hline TV & 2 & 2.13 & 92 & 97.87 \\
\hline \multicolumn{5}{|c|}{ What is PCOS (Polycystic ovarian syndrome)? } \\
\hline No idea & 56 & 59.57 & 38 & 40.43 \\
\hline Presence of cancerous cells in the ovaries & 0 & 0 & 16 & 17.02 \\
\hline $\begin{array}{l}\text { The presence of fluid filled sacs in the ovaries } \\
\text { leading to an imbalance in the female sex } \\
\text { hormones }\end{array}$ & 36 & 38.30 & 2 & 2.13 \\
\hline $\begin{array}{l}\text { The presence of solid fluid filled sacs in the } \\
\text { ovaries leading to an imbalance in female sex } \\
\text { hormones }\end{array}$ & 18 & 19.15 & 18 & 19.15 \\
\hline $\begin{array}{l}\text { PCOS (Polycystic ovarian syndrome) is a curable } \\
\text { disease }\end{array}$ & 22 & 23.40 & 12 & 12.77 \\
\hline PCOS is a major cause of infertility & 16 & 17.02 & 18 & 19.15 \\
\hline PCOS is a chronic / Life- long disease & 10 & 10.64 & 24 & 25.53 \\
\hline Hormonal imbalance is a key feature of PCOS & 28 & 29.79 & 2 & 2.13 \\
\hline \multicolumn{5}{|c|}{ What major organ is affected by PCOS? } \\
\hline No idea & 34 & 36.17 & 60 & 63.83 \\
\hline Fallopian tube & 4 & 4.26 & 2 & 2.13 \\
\hline
\end{tabular}




\begin{tabular}{|c|c|c|c|c|}
\hline Ovaries & 44 & 46.81 & 2 & 2.13 \\
\hline The womb & 18 & 19.15 & 0 & 0 \\
\hline Cervix & 4 & 4.26 & 4 & 4.26 \\
\hline Are you aware if PCOS is treatable? & 40 & 42.55 & 54 & 57.45 \\
\hline \multicolumn{5}{|c|}{ What are your perceived Key Clinical Features of PCOS? } \\
\hline Irregular menstrual cycles/periods & 82 & 87.23 & 12 & 12.77 \\
\hline Hormone imbalance & 68 & 72.34 & 26 & 27.66 \\
\hline Cysts in ovaries & 66 & 70.21 & 28 & 29.79 \\
\hline Insulin resistance & 8 & 8.51 & 96 & 91.49 \\
\hline Increased tendency for weight gain & 44 & 46.81 & 50 & 53.19 \\
\hline Reduced fertility or infertility & 52 & 55.32 & 42 & 44.68 \\
\hline Excess hair growth & 54 & 57.45 & 40 & 42.55 \\
\hline $\begin{array}{l}\text { Increased risk of metabolic complications (type } 2 \\
\text { diabetes/ gestational diabetes/ cardiovascular } \\
\text { disease) }\end{array}$ & 2 & 2.13 & 92 & 97.87 \\
\hline Mood disorders (depression and anxiety) & 2 & 2.13 & 92 & 97.87 \\
\hline
\end{tabular}

Table 3: Concentration of Female Reproductive Hormones in PCOS and non-PCOS patients

\begin{tabular}{llll}
\hline Reproductive Hormones & $\begin{array}{l}\text { Concentration in Non- } \\
\text { PCOS females(miu/ml) }\end{array}$ & $\begin{array}{l}\text { Concentration in PCOS } \\
\text { females(miu/ml) }\end{array}$ & Significance (P-value) \\
\hline LH & $8.04 \pm 0.77$ & $14.28 \pm 2.32^{*}$ & 0.01 \\
FSH & $5.90 \pm 0.17$ & $9.56 \pm 1.63^{*}$ & 0.03 \\
PROGESTERONE & $27.12 \pm 1.58$ & $14.73 \pm 3.00^{*}$ & 0.01 \\
PROLACTIN & $20.42 \pm 0.98$ & $23.25 \pm 3.65$ & 0.45 \\
\hline
\end{tabular}

\section{DISCUSSION OF RESULTS}

\section{Distribution of Respondents by Socio-Demographic Characteristics}

In this study $59.57 \%$ of respondents were between the ages of $21-30$ years of age, followed by $26.60 \%$ of respondents between the ages 31-40 years of age, $8.52 \%$ respondents between the ages of 11-20 years of age and 5.32\% of them were above 40 years. Most of the respondents $(51.06 \%)$ were married, $42.55 \%$ were single while $6.38 \%$ were divorced. Concerning the educational status of the respondents, $51.06 \%$ of them have acquired tertiary education, $40.43 \%$ of them have secondary education while only $8.51 \%$ of them had acquired primary school education. Regarding the weight of the respondents, majority (40.43\%) of them was overweight, $27.66 \%$ of them had normal weight and the same percentage was also obese while $4.26 \%$ of them were extremely obese. Concerning the age 
of diagnosis, $89.36 \%$ of them were middle-aged (18-45 years), $10.64 \%$ of them were adolescence (less than 18 years) while none of them was above 45 years of age.

This study's respondents were mainly within the age range of 21-30 years. It can therefore be assumed that PCOS is mainly found among women within the age range of 21 to 30 years of age. ${ }^{[5]}$ It has been reported in a similar result that the most abundant age range of the respondents with PCOS was found to be between 15 to 25 years. ${ }^{[6]}$ Regarding the relationship between the weight of the respondents and their tendencies of developing PCOS, Overweight or obesity is said to affect approximately $60-80 \%$ of PCOS patients. ${ }^{[7]}$ It has also been found that the majority of women with PCOS (38\%-88\%) are either overweight or obese. ${ }^{[8]}$ Data from the Northern Finland Birth Cohort (NFBC) 1966 shows a significant association between body mass index (BMI) and features of PCOS at all ages. ${ }^{[9]}$ Furthermore, modest weight-loss (around 5\%) often results in clinically meaningful improvements in the reproductive hyperandrogenism and metabolic features of PCOS. ${ }^{[10]}$ It has been found that in obese women with PCOS, there are often features like hirsutism, menstrual irregularities, and fertility problems that amalgamate with the already complex interlinks between obesity and mental and emotional functioning. In one cross-sectional and self-reported study on 177 women with PCOS and 109 healthy controls, scores for anxiety, depression, and negative body image were significantly higher in the women with PCOS. ${ }^{[11]}$ In another cross-sectional study on 50 patients with PCOS and 41 healthy controls, women with PCOS had significantly higher depression and anxiety scores when compared with the controls. ${ }^{[12]}$

\section{Knowledge of Respondents about PCOS}

When asked if they had heard about PCOS, most respondents (59.57\%) indicated that they have not heard of PCOS while only $40.43 \%$ indicated that they have heard about the condition before. Among the respondents who have heard about it, $21.28 \%$ claimed that they heard about it from health workers, $21.28 \%$ said that they heard about it from the internet, $12.77 \%$ reportedly heard about it from relatives, $10.77 \%$ from the newspaper while only $2.13 \%$ respondent reportedly heard about it from the television. Regarding the meaning of PCOS, $59.57 \%$ respondents confessed that they don't know the meaning while only $40.43 \%$ said they know the meaning of the condition. Among the respondents who claim to know the meaning of the condition, $17.02 \%$ said that it refers to the presence of cancerous cells in the ovaries, $38.30 \%$ said that it is the presence of fluid filled sacs in the ovaries leading to an imbalance in the female sex hormones, $19.15 \%$ said that it is the presence of solid fluid filled sacs in the ovaries leading to an imbalance in female sex hormones, 23.4\% said that PCOS (Polycystic ovarian syndrome) is a curable disease, 23.4\% believed that PCOS (Polycystic ovarian syndrome) is a curable disease, $17.02 \%$ said that PCOS is a major cause of infertility while $29.79 \%$ believed that Hormonal imbalance is a key feature of PCOS. When asked about the major organ(s) affected by PCOS, $36.17 \%$ of them confessed that there was no idea, $46.81 \%$ of them said it is the ovaries, $19.19 \%$ of them said it is the womb while $4.26 \%$ said it is the fallopian tube. When asked whether PCOS is treatable, $57.45 \%$ said no while $42.55 \%$ answered in the affirmative. Concerning the respondents' perceived key

www.scirj.org

(C) 2021, Scientific Research Journal

http://dx.doi.org/10.31364/SCIRJ/v9.i10.2021.P1021890

This publication is licensed under Creative Commons Attribution CC BY. 
clinical features of PCOS, 87.23 reported irregular menstrual cycles/periods, $72.34 \%$ hormone imbalance, $70.12 \%$ cysts in ovaries, 57.45 Excess hair growth and $2.13 \%$ responded mood disorders (depression and anxiety).

Generally, the knowledge of the respondents about PCOS was poor with only $40.43 \%$ of the respondents indicating having knowled ge about it. This finding therefore disagrees with that of others, who reported a higher percentage where up to $65 \%$ had heard about PCOS. ${ }^{[5]}$ This difference in finding may be attributable to the wider coverage of study setting such that the higher sample size of the researcher might have contributed to this higher percentage difference. However, in a study in India, a lower percentage of participants who knew about PCOS were reported. ${ }^{[13]}$ Other studies have also reported the knowledge of the respondents about the condition to be below average. ${ }^{[14,15]}$

Furthermore, when the respondents were asked from where they had heard about PCOS, they indicated that primary health workers and the internet were their sources of the information. A similar result was obtained in a study were healthcare professionals were the primary source of the information of the respondents about the condition ${ }^{[16]}$ It can be said that the respondents in this study are constantly involved in surfing the web and therefore might have come across PCOS information related to other issues of reproduction sought after. In a work done by a group of researchers, respondents were found to have been diagnosed of PCOS and so it was most likely they have had contact with healthcare providers, hence were majorly informed by the healthcare providers. ${ }^{[17]}$

\section{Effects of PCOS on the Concentration of the Female Reproductive Hormones in PCOS patients}

It has been found from this study that PCOS condition significantly elevated the concentrations of Luteinizing hormone (LH) and Follicle-stimulating hormone (FSH) and significantly reduced the concentration of Progesterone ( PGS) with respect to the non-PCOS patients. It was also found to have an insignificant effect on the concentration of prolactin.

In a work done on the effect of Polycystic Ovarian Syndrome on the Lipid Profile and sexual hormones, the statistical analysis of PCOS women showed a significant increase in the level of luteinizing hormone (LH), follicular stimulating hormone (FSH), and testosterone and a significant decrease in the progesterone level with respect to the control (non-PCOS women) group at a significant level of $0.05 .{ }^{[18]}$ The results of studies conducted by other scientists showed a significant increase in the level of the LH and FSH. ${ }^{[19]}$ Also, the results of other studies showed a significant increase in the levels of LH, FSH and testosterone of PCOS patients with respect to the control group. ${ }^{[20]}$

However, this result contradicts that of a study conducted on PCOS women, which showed an increase in the levels of LH, testosterone and androstenedione (a progesterone derivative) and a decrease in FSH level in the PCOS group, when compared with the control. ${ }^{[21]}$

www.scirj.org

(C) 2021, Scientific Research Journal

http://dx.doi.org/10.31364/SCIRJ/v9.i10.2021.P1021890

This publication is licensed under Creative Commons Attribution CC BY. 
The observed hyperandrogenism in this study is one of the main signs of polycystic ovarian syndrome and may be attributed to increased level of insulin hormone and its effect on theca cells of the ovary. It has been said that as a result of the dysfunctional ovarian steroid-genesis which is the main pathophysiological abnormalities in PCOS women, theca cells from those PCOS patients will show an increased androgen secretion when they are cultured separately in vivo. ${ }^{\text {[2] }}$ This state of hyper androgenaemia will alter the microenvironment within the follicles, leading to an impaired folliculogenesis. ${ }^{[22]}$ High androgen level has a deleterious effect on folliculogenesis resulting in follicular atresia. The hyper androgenic state can also lead to a disturbed meiotic division as well as mitotic division of the oocytes, which in turn results in improper maturation of the oocytes and developmental compromise. ${ }^{[23]}$ It is a known fact that both LH and FSH are necessary for enhancement of follicular growth and secretion of E2 and testosterone within a threshold level to oppose the inhibitory signals that holds meiosis in prophase I in the normal ovary and allow oocytes initiate and complete meiosis.

An excess LH production which may be due to the failure of normal ovulation, alter the micro-follicular environment leading to the production of bad quality oocytes and embryos and decrease uterine receptivity to the developed embryos which in turn decreases the chance of the women to get a spontaneous pregnancy. Also, a raised concentration of LH, together with premature LH surge, may have an impact on follicle and oocyte development and are believed to be responsible for lowering pregnancy rate in those patients. A long time exposure of oocytes to high LH concentrations also leads to impairment of cytoplasmic maturity of oocytes.

In PCOS patients, the increasing level of androgen usually leads to a decreased ovum potential to produce top-quality embryo. A high serum androgen level also has a negative impact on the quality of embryo itself and its quality gradually deteriorated with increased patients' age. It has been found that the embryos of PCOS women with high serum androgen and an age more than 35 years are usually at an increased risk of developmental arrest. ${ }^{[24]}$ PCOS women with hyper androgenaemia and obese women had shown delayed early embryonic developmental stages. Embryos which were derived from such women were characterized by delayed two pronuclei $(2 \mathrm{PN})$ formation post injection and delayed 4 cell stage up to 8 cell stage developments [25]. However, this delay in the embryonic development had no significant bad impact on implantation and pregnancy rate. ${ }^{[26]}$

Several studies have suggested a link between the hyper-secretion of LH specifically and early miscarriage. It has been said that an elevated LH concentration can cause premature maturation of oocytes, release a physiologically aged oocytes and make viable embryos therefore unlikely to be produced. ${ }^{[27]}$ Also, an elevated LH concentration can lead to impairment of the endometrial receptivity resulting in implantation failure.

Hyperandrogenism represents a chief attribute of PCOS because elevated androgen levels are the most constant feature of PCOS, with the majority $(60 \%)$ of patients exhibiting hyperandrogenism. Women with hyper-androgenic PCOS have been found to present with elevated levels of various androgens, including testosterone ( $\mathrm{T}$ ) and the pro-androgens androstenedione (A4) and 
dehydroepiandrosterone sulfate (DHEAS), as well as the enzyme required to convert pro-androgens to bioactive androgens, 3 hydroxysteroid dehydrogenase (3 -HSD) in serum. ${ }^{[28]}$ The ovarian PCOS morphological traits of enlarged, multi-cystic ovaries and theca interstitial hyperplasia are reported in women who are subjected to high levels of androgens as a result of endogenous adrenal androgen hypersecretion in congenital adrenal hyperplasia. ${ }^{[29]}$ It can be postulated therefore that a prolonged pituitary suppression could be helpful in PCOS patients.

\section{CONCLUSION}

The results of this study showed that PCOS tends to be more prevalent among women within the age range of 21-30 years; the women in this study generally have a poor knowledge about the meaning, symptoms and etiology of PCOS. Finally, it was found that PCOS has the capacity to cause hormonal imbalance which can negatively affect the reproductive capacity of the patients. It is necessary to perform an early and periodic examination of the sex hormones in women with PCOS in order to reduce complications.

\section{ETHICAL APPROVAL}

Ethical approval was secured by the authors from the ethics committee of the universities.

\section{ACKNOWLEDGEMENTS}

The authors would like to express warm appreciation to Professors D.V Dapper and I.M Siminialayi of the Department of Human Physiology and Pharmacology respectively, College of Health Sciences, University of Port Harcourt, Nigeria for their immense technical assistance

\section{SOURCE OF FUNDING}

None

\section{COMPETING INTERESTS}

Authors have declared that no competing interests exist.

\section{AUTHOR'S CONTRIBUTION}

Author Oriji Eunice Ibiye conceived the study, designed the protocol and contributed in the manuscript writing while author Ojeka Sunday Ogbu coordinated the experiment, carried out the laboratory procedures. Finally, author Zabbey Victor Zigabelbari performed the statistical analysis and data interpretation. All authors read through and approved the final manuscript.

\section{REFERENCES}

1 Rahul Pal, Pratik Kumar Chatterjee, Poulomi Chatterjee, Vinodini NA, Prasanna Mithra, Sourjya, Banerjee, Suman VB, Sheila R. Pai (2014). Polycystic ovary syndrome, blood group and diet: A correlative study in south Indian females. Int J Med Res Health Sci. 3(3):604-609

Lori Smith (2018.). What is polycystic ovary syndrome? Medical news today newsletter.

3 Erin K. Barthelmess1 and Rajesh K. Naz (2014). Polycystic ovary syndrome: current status and future perspective. Front Biosci (Elite Ed). 6: 104-119.

4 Boomsma CM, Eijkemans MJ, Hughes EG, Visser GH, Fauser BC, Macklon NS. (2006). A meta-analysis of pregnancy outcomes in women with polycystic ovary syndrome. Hum Reprod Update. 12(6):673-83.

5 Olotu JE, Okon M. (2020). "Awareness of Polycystic Ovarian Syndrome among Young Female Adults in Nigeria". EC Endocrinology and Metabolic Research. 5(8):21-26.

www.sciri.org

(C) 2021, Scientific Research Journal

http://dx.doi.org/10.31364/SCIRJ/v9.i10.2021.P1021890

This publication is licensed under Creative Commons Attribution CC BY. 

Nursing Students at NUINS. Nitte University Journal of Health Science. NUJHS. 6(3): 24-26.

Azziz R, Woods KS, Reyna R, Key TJ, Knochenhauer ES, Yildiz BO (2004). The prevalence and features of the polycystic ovary syndrome in an unselected population. J Clin Endocrinol Metab. 89:2745-9.

Barber, TM, McCarthy, MsI, Wass, JA, Franks, S. (2006): Obesity and polycystic ovary syndrome. Clin Endocrinol (Oxf). 65:137-145.

Ollila, MM, Piltonen, T, Puukka, K (2016). Weight gain and Dyslipidaemia in early adulthood associate with polycystic ovary syndrome: prospective cohort study. J Clin Endocrinol Metab. 101:739-747.

Holte, J, Bergh, T, Berne, C, Wide, L, Lithell, H. (1995): Restored insulin sensitivity but persistently increased early insulin secretion after weight loss in obese women with polycystic ovary syndrome. J Clin Endocrinol Metab. 80:2586-2593

Karjula S, Morin-Papunen L, Auvinen, J (2017). Psychological Distress Is More Prevalent in Fertile Age and Premenopausal Women With PCOS Symptoms: 15-Year Follow-Up. J Clin Endocrinol Metab.102:1861-1869.

Ozturk A, Kucur SK, Seven A (2019). Temperament and character differences of patients with polycystic ovary syndrome. $J$ Gynaecol Obstet Hum Reprod.48:255-259.

Patel J. Rai. S. (2018): Polycystic ovarian syndrome (PCOS) awareness among young women of central India. Int J Reprod Contracept Obstet Gynecol.7 (10):3960-3964

Dalal M, Babu M, Rastogi S. (2014). An Exploratory Survey to Assess the Knowledge, Practice An Prevalence Of Polycystic Ovarian Syndrome Among Women Attending Gyne OPD Of Selected Hospital Of Delhi With A View To Develop A Health Care Package On Polycystic Ovarian Syndrome And Its Management. IOSR Journal of Nursing and Health Science. 3(6): 39-42 25.

Avery JC, Braunack-Mayer AJ. (2007). The information needs of women diagnosed with Polycystic Ovarian Syndrome-implications for treatment and health outcomes. BMC Womens Health. 7: 9.

Rao M, Broughton KS, LeMieux M. (2020). Cross-sectional Study on the Knowledge and Prevalence of PCOS at a Multiethnic University, Progress in Preventive Medicine. 5(2): p e0028

Jaya Patel, Shailesh Rai (2018). Polycystic ovarian syndrome (PCOS) awareness among young women of central India. International Journal of Reproduction, Contraception, Obstetrics and Gynecology. 7(10):3960-3964

Homburg R. (2006): Pregnancy complications in PCOS. Best Pract Res Clin Endocrinol Metab. 20(2):281-92.

Oti-wilberforce RO, Onyeanusi JC, Nworie A, Oti Wilberforce JO (2016). Investigation Of Levels Of Luteinizing Hormone and Follicular Stimulating Hormone Among Women With Polycystic Ovary Syndrome In Abakaliki, Nigeria. IOSR Journal of Nursing and Health Science (IOSR-JNHS). 5 (40): 104-107. patients with polycystic ovary syndrome in relation to body mass index. International Journal of Current Research. 7 (01): 11919-11922. production. Hum Reprod.13 (2):290-293.

Walters KA and Handelsman DJ (2016). Androgen receptor splice variants and polycystic ovary Syndrome: cause or effect? Asian J. Androl., 18:442-443.

www.scirj.org

(C) 2021, Scientific Research Journal

http://dx.doi.org/10.31364/SCIRJ/v9.i10.2021.P1021890

This publication is licensed under Creative Commons Attribution CC BY. 
23 Yan Z, Lingyan L, Tai-Lang Y, Jing Y, Cheng-Liang X (2016). Follicular metabolic changes and effects on oocyte quality in polycystic ovary syndrome patients. Oncotarget.1, 8 (46):80472-80480.

24 Baoli Y, Haoying H, Duo W, Xiaobing S, Juanke X, Cuilian Z. (2015). Patients with polycystic ovary syndrome have a successful embryo arrest. Int. J. Clin. Exp. Med. 8(4):6247-6251.

25 Wissing, M.L., Bjerge, M.R., Hoest, T., and Mikkeilsen, A.L. (2014): Impact of PCOS on early embryo cleavage kinetics. Reproductive Bio-Medicine online. 18:508- 514.

26 Bellver, J., Mifsud, A., Grau, N., Privitera, L., and Meseguer, M. (2013): Similar Morphokientic patterns in embryo derived from obese and norm oweight infertile women: a time-lapse study. Hum.Reprod.,28: 794-800.

27 Revelli A, Piane LD, Casano S, Molinari E, Massobrio M, Rinaudo P (2009). Follicular fluid content and oocyte quality from single biochemical markers to metabolomics. Reprod. Biol. Endocrinol.7:1-13.

28 Livadas S, Pappas C, Karachalios A, Marinakis E, Tolia N, Drakou M, Kaldrymides P, Panidis D, Diamanti-Kandarakis E (2014). Prevalence and impact of hyperandrogenemia in 1218 women with polycystic ovary syndrome. Endocrine. 47, 631638.

29 Keefe CC, Goldman MM, Zhang K, Clarke N, Reitz RE, Welt CK (2014). Simultaneous Measurement of Thirteen Steroid Hormones in Women with Polycystic Ovary Syndrome and Control Women Using Liquid Chromatography-Tandem Mass Spectrometry. 9, 93805 . 